\title{
NON-EPILEPTIC SEIZURES WITH INTERICTAL SPIKES
}

Long-term EEG-video-monitoring (LTM) detected 12 (8\%) patients with non-epileptic seizures (NESs) among 145 temporal lobectomy candidates with medically refractory seizures and interictal temporal EEG spikes in a study at Emory University School of Medicine, Atlanta, GA. Seven patients had epileptic seizures recorded and characterized by motionless staring in addition to NESs. LTM performed in temporal lobectomy candidates permits exclusion of those with NESs. (Henry TR, Drury I. Non-epileptic seizures in temporal lobectomy candidates with medically refractory seizures. Neurology May 1997;48:13741382). (Reprints: Dr Thomas R Henry, Department of Neurology, Emory University, Woodruff MRB, Ste 6000, 1639 Pierce Drive, Atlanta, GA 30322).

COMMENT. Long-term EEG video-monitoring and ictal recordings are important pre-surgical evaluations in patients with medically refractory temporal lobe seizures and interictal temporal lobe spikes. Non-epileptic seizures are sometimes uncovered, though definitive exclusion of epileptic seizures may require intracranial EEG recordings.

\section{SEIZURE DISORDERS}

\section{EPILEPSY SURGERY OUTCOME IN CHILDREN}

Seizure frequency, neuropsychological function, quality of life, and need for antiepileptic drugs were evaluated in 33 consecutive children following epilepsy surgery at 12 years of age or younger at the University of Alabama at Birmingham and the Cleveland Clinic Epilepsy Centers. Two thirds were seizure-free after a mean follow-up of 3 years, and only 4 showed no improvement. Antiepileptic drugs were discontinued in $30 \%$, and a similar percentage of patients tested psychologically showed a more than 10 point improvement in Verbal or Performance IQ. One patient had a mild hemiparesis and another a quadrantanopia. Inferior scores noted in quality of life questionnaires were unexplained. (Gilliam F, Wyllie E, Kashden J, Faught E, Kotagal P et al. Epilepsy surgery outcome: Comprehensive assessment in children. Neurology May 1997;48:1368-1374). (Dr Frank Gilliam, UAB Epilepsy Center, 1719 6th Avenue South, Suite 312, Birmingham, AL 35294).

COMMENT. This study confirms that surgery can be an effective treatment of refractory epilepsy in children, and surgical complications are unusual. The selection of patients is aided by video/EEG monitoring of seizures, intracranial monitoring or electrocorticography at the time of surgery, and PET or ictal SPECT imaging in some cases.

\section{RISK FACTORS IN FEBRILE SEIZURE RECURRENCE}

Predictors of single and mutiple recurrent febrile seizures were identified prospectively in 428 children with first febrile seizures followed for 2 or more years at the Yale-New Haven Hospital, Jacobi Medical Center, North Central Bronx Hospital, and Montefiore Medical Center, Albert Einstein College of Medicine, NY. Of 136 (32\%) having recurrent seizures, $17 \%$ had one recurrence, $9 \%$ had 2 recurrences, and $6 \%$ had 3 or more recurrences. Predictors of recurrent febrile seizures were: 1) young age at onset; 2) a family history of febrile seizures; 3) low degree of fever, and 4) brief interval between onset of fever and the first seizure. (Berg AT, Shinnar S, Darefsky AS et al. Predictors of recurrent febrile seizures. A prospective cohort study. Arch 
Pediatr Adolesc Med April 1997;151:371-378). (Reprints: Anne T Berg PhD, Department of Biological Sciences, Northern Illinois University, DeKalb, IL 60115).

COMMENT. This study is one further confirmation of well established risk factors for recurrences of febrile seizures, especially age at onset, family history, and height of fever. (see Progress in Pediatric Neurology II, 1994;pp23-24; and Vol III, 1997;p29). A threshold to febrile seizures based on height of body temperature was established in animal and clinical studies performed 40 years previously at the Albert Einstein College of Medicine, NY. (Millichap JG. Studies in febrile seizures I. Height of body temperature as a measure of the febrile seizure threshold. Pediatrics Jan 1959;23:76-85).

A clinical study of 5 cases of epilepsy beginning as severe febrile seizures and seizures induced by hot water baths is reported from Ehime University, Japan. (Fukuda M, Morimoto T, Nagao H, Kida K. Brain Dev April 1997;19:212-216). Febrile seizures were controlled by clonazepam and diazepam but not by phenobarbital or valproate.

\section{RASMUSSEN'S SYNDROME: EEG STUDY}

The early and follow-up EEG characteristics of Rasmussen's syndrome are reported in an 11-year-old girl studied at Ospedale Civile, Mantova, Italy. Delta activity localized to the left temporal region persisted in the EEG three days following an initial 15 min partial seizure characterized by staring, right arm parasthesias, and speech impairment. Neurologic exam and MRI were normal. SPECT scan showed left temporal hypoperfusion. Recurrent partial focal clonic seizures responded to steroid therapy but relapsed when treatment was discontinued after 2 months. Epilepsia partialis continua developed, and the EEG showed a spike focus complicating the continuous slow activity in the left rolandic region. A repeat MRI showed mild rolandic cortical atrophy. After 2 years, the patient was aphasic, hemiplegic, and mentally deteriorated, and seizures were refractory to antiepileptic drugs, corticosteroids, and alpha globulins. Plasmapheresis was of little benefit. (Capovilla G, Paladin F, Bernadina BD. Rasmussen's syndrome: longitudinal EEG study from the first seizure to epilepsia partialis continua. Epilepsia April 1997;38:483-488). (Reprints: Dr G Capovilla, Department of Neuropediatrics, Ospedale Civile di Mantova, Mantova, Italy).

COMMENT. The EEG may help in the early diagnosis of Rasmussen's syndrome in a child with partial seizures complicated by speech impairment and normal MRI. Focal delta activity without epileptiform spikes may preceed the onset of epilepsia partialis continua by several months.

\section{LANDAU-KLEFFNER SYNDROME: IV g-GLOBULIN RESPONSE}

An 8-year-old girl with Landau-Kleffner syndrome failed to respond to antiepileptic drugs and steroids but showed clinical and EEG improvement after intravenous g-globulin therapies at the American University of Beirut School of Medicine, Lebanon. Mumps at 5 years of age was complicated by receptive and expressive aphasia. An EEG showed generalized spike and slow waves, and a trial of valproate (VPA) was ineffective. At 6 years, the neurologic exam, apart from aphasia, the CT and MRI were normal, and the EEG showed almost continuous left-sided spike and slow wave complexes, resistant to VPA, clonazepam, and prednisone. Three courses of iv immunoglobulins, 400 $\mathrm{mg} / \mathrm{kg} /$ day for 5 days, at 6 -month intervals, resulted in a normal EEG and near-normal speech. CSF IgG index, previously increased, returned to normal 